\title{
Proposed opioid prescribing guidelines meet backlash
}

\author{
- Cite as: CMAJ 2017 February 21;189:E290-1. doi: 10.1503/cmaj.1095393
}

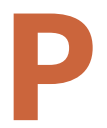

roposed opioid prescribing standards for chronic pain would more than halve the maximum daily dose and discourage prescribing to patients with substance use disorders and serious mental illness.

Canada's opioid guidelines haven't been updated since 2010. Meanwhile, overprescribing of the powerful painkillers has contributed to an epidemic of addiction and death. Health Canada funded the Michael G. DeGroote National Pain Centre at McMaster University in Hamilton to develop new guidelines to help tackle the problem.

The draft recommendations reflect better evidence, patient input and protections against conflicts of interest, says Jason Busse, who chaired the project. But some patient advocates say the

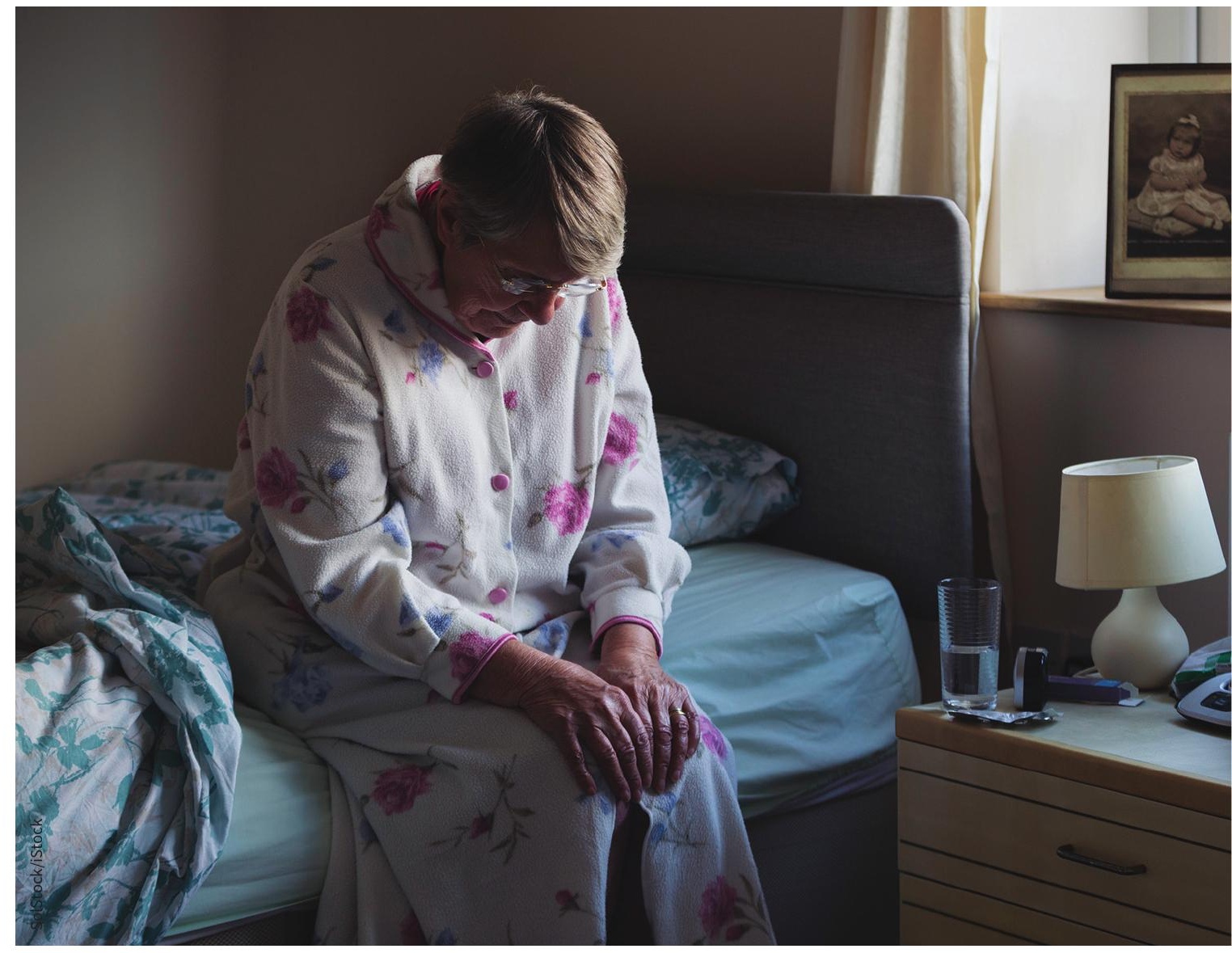

Some patients fear reduced access to necessary pain relief with proposed changes to opioid prescribing for chronic non-cancer pain.

proposed limits are too restrictive and discriminatory, and may push people to use illicit drugs instead.

The proposed guidelines urge doctors to try other treatments before starting a trial of opioids, and then limit the maximum daily dose to 50-90 mg morphine equivalents. This threshold is much lower than the current recommended cap of 200 mg morphine equivalents per day, and mirrors recent American recommendations.

But where the American guidelines are based on expert opinion and "zero studies," the new Canadian advice is based on evidence from "100 randomized controlled trials," says Busse. About $75 \%$ of these studies prescribed patients an average dose of less than $90 \mathrm{mg}$ morphine equivalents, he says. "There really isn't good evidence for most people that they will achieve greater pain relief if they go to a higher dose."

Patients with chronic pain say they weigh the risks and benefits differently. "Pain patients rely on their medications. Some are dependent upon it to live their lives," says Terry Bremner of the Chronic Pain Association of Canada. "It's ludicrous to think that you're going to take someone that's functioning fine today and take away three-quarters of their medication and they'll be okay."

Bremner fears that the proposed guidelines will make legitimate access to opioids more difficult, if not impossible, driving some people to use illegal alternatives or take drastic measures to end their suffering. "Right now, even without these guidelines, there are people that aren't 
getting medication," he says. "Some of them will end up getting arrested. Some of them will end up committing suicide. I get those calls, too."

The draft guidelines recommend weaning patients off higher doses as much as possible, and advise against prescribing opioids to patients with past or current substance use disorders, or serious psychiatric disorders that are not stabilized.

Bremner worries that some patients will cover up addiction and mental health problems as a result, leading to bigger problems down the line. "Seeing some of these guidelines, l'd be biting my tongue," he says.

Sean LeBlanc, founder of the Drug User Advocacy League, calls the proposed restrictions "typical anti-drug consumer stigma."

"Pain is pain and disqualifying a group because they previously consumed opioids improperly is discriminatory, wrongheaded and frankly, cruel and against the Hippocratic Oath," he says.

Busse says that the guidelines team heard similar concerns from its patient advisory panel. "It was surprising, to me at least, the very high value that patients living with chronic pain place on even modest pain relief, even in the face of frequent risks of serious consequences," he says. For that reason, the proposed guidelines include a caveat that "some patients may gain important benefit over $90 \mathrm{mg}$ morphine equivalents," and should be referred for a second opinion.

However, when it came to patients with current substance use disorders or unmanaged psychiatric illness, "we felt there was sufficiently high risk in these groups that we were comfortable recommending against a trial of opioids," Busse says.

In an accompanying document, the guidelines team explained that they weighed "societal values," such as avoiding addiction as more important in these cases. "Desperation for any relief from chronic pain ... may leave some patients vulnerable to short-term decisions," the document states. Patients on the advisory panel who had suffered harms from opioids "placed a much higher value on their avoidance."

Busse says the guidelines team took particular care to guard against "intellec- tual conflicts of interest" for this reason. Experts and patients who had "planted a flag on one side of the debate or the other" could advise but not vote on the draft recommendations, he explains. "It was one of the only ways we could get people with diametrically opposing viewpoints to work together."

The reaction of these advisers to the proposed guidelines has been similarly split, Busse says. In the case of the daily dose restrictions, "two people looked at the same recommendation, with one saying this is sufficiently restrictive that you are going to deny a lot of people appropriate care, and another saying this is sufficiently permissive that you are going to lead to harm in a number of patients."

"It's all but impossible to reconcile these two extremes," Busse says.

The guidelines team will review public feedback on the proposed recommendation over the next month and use that to develop a final draft for Health Canada in March.

Lauren Vogel, CMAJ 